\title{
Optimization of the width of the transportation corridor of tractor trains for agricultural purpose
}

\author{
A. N. Kushnarev*, E. E. Kuznetsov, S. V. Shchitov, V. G. Evdokimov, and E. I. Reshetnik \\ Far Eastern State Agrarian University, Polytechnicheskaya street, 86, Blagoveshchensk
}

\begin{abstract}
The main works related to the production and transportation of crop production take place in the Amur region in conditions when the surface of the movement has a weak carrying capacity, which imposes additional requirements on transport units to increase their traction-chain properties.So the issue of exporting crop products from the fields is important and relevant both for peasant farms (PF) and for private farms. The use of multi-link tractor trains (MTU) in the region is limited by a significant deterrent, such as the increase in the width of the transport corridor in turns. Why the issue of increasing the efficiency of the ICC should be considered both in the direction of increasing traction-chain properties, and at the same time optimizing the width of the transport corridor when it moves. The proposed article provides theoretical, experimental research and experience with the use of the designer and scientific novelty, designed to enhance traction-clutch properties and reduce the width of the MTU corridor in an arbitrary turn.
\end{abstract}

\section{Introduction}

It is possible to increase the efficiency of using wheeled mobile power-tractors as part of tractor-transport units by increasing the volume (mass) of the transported cargo [1]. The main limiting factor in this case is the insufficient traction and coupling properties of tractors with a wheeled chassis during the transportation of agricultural goods from the fields. This issue is especially acute in small farms, where the main energy source is universal row-crop tractors with a wheel arrangement of 4K2. The analysis of the known methods of increasing the efficiency of using these tractors showed that it is possible to solve this problem for improving their traction and coupling properties [2, 3].

The works of a significant number of researchers are devoted to the improvement of the traction-coupling properties of wheeled tractors [4,5]. At the same time, the methods considered and proposed by them to increase the traction and coupling properties may not always be acceptable, since their application does not take into account changes in the natural production and road conditions of the region where they are operated.

In the conditions of the Amur Region, the main transportation operations associated with the transportation of goods from the fields occur during the period when the main

\footnotetext{
* Corresponding author: leha.kushnarev.79@gmail.com
} 
amount of precipitation falls. Consequently, the transportation of goods occurs along field dirt roads, which have a significant number of sections associated with a change in rectilinear movement, that is, with turns having a weak bearing surface.

Another limiting factor in the use of multi-link tractor-transport trains is the small width of the carriageway and, therefore, when cornering, they cannot withstand the optimal width of the transport corridor, which affects traffic safety.

In connection with the above, in the conditions of the road network of the Amur region and regions with a small width of the carriageway of agricultural roads, in order to increase the efficiency of the use of tractor trains, it is necessary to follow the path of increasing the traction and coupling properties of wheeled energy vehicles with simultaneous optimization of the width of the transport corridor [6]

In earlier studies, it is noted that the optimization of the transport corridor can be carried out by shifting the attachment point of the towing device of the power unit and the trailer, depending on the direction of rotation.

In the studies carried out in the works, it is noted that the displacement of the attachment point of the trailer to the energy device contributes to an increase in the tractioncoupling properties of tractors due to the redistribution of the coupling weight inside the machine-tractor unit.

Thus, taking into account the hypothesis formulated, the aim of the work is to conduct a patent search and create a reliable, high-performance device with a low cost, which allows to automatically increase the traction-coupling properties of an energy vehicle at a turn, while optimizing the width of its transport corridor.

\section{Material and Methods}

An example of the above-mentioned device is the use of a device of a new design, which, due to the displacement of the attachment point of the trailer and the tractor, can achieve a redistribution of the coupling weight, and, consequently, an increase in its traction and coupling properties, while simultaneously optimizing the transport corridor.

For this purpose, it is proposed to install on the tractor a hydro-regulated towing device with an inventive level and novelty [7], which will allow achieving a significant and effective result (Figure 1-2).

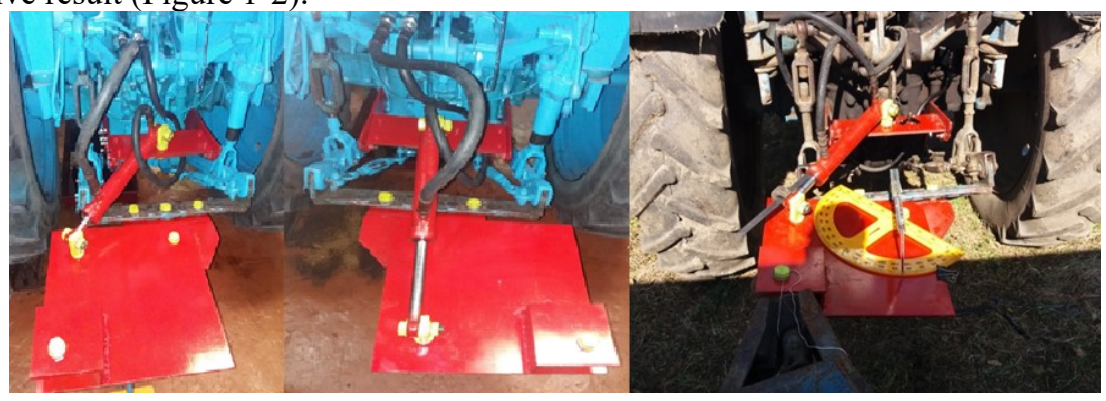

Fig. 1. Experimental hydraulically adjustable towing device 

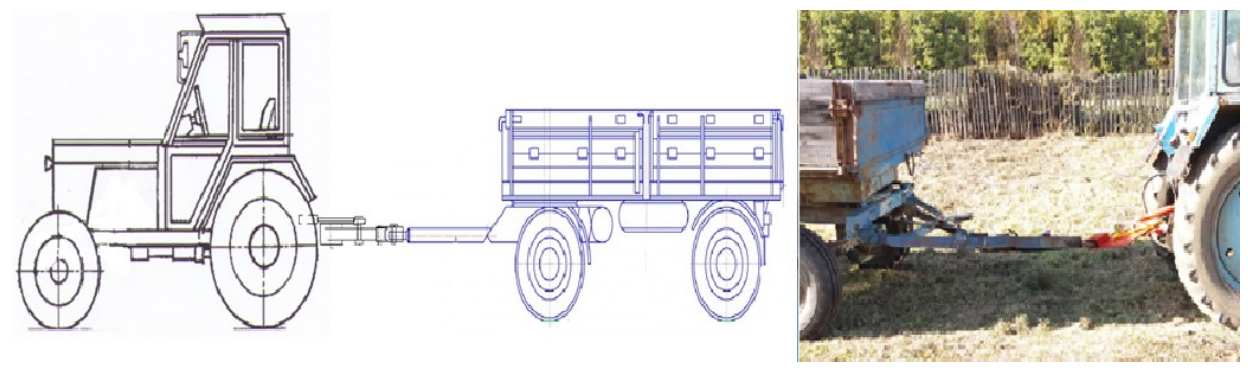

Fig. 2. Connection diagram of a trailer with a tractor through a hydraulic adjustable towing device

As an object for the study of traction and coupling properties and an experiment to optimize the width of the corridor, a wheeled tractor was taken, as it is the most often used in small farms in the agricultural sector of the region, with an experienced hydro-adjustable towing device.

The studies were carried out according to the recommended general and specific methods using specialized programs for mathematical calculation, experiment modeling and methods of regression analysis [8]. At the same time, the following parameters were measured: adhesion weight, turning radius, turning angle of the guide wheels, changing the attachment point of the trailer to the tractor, the length of the hydraulic cylinder rod outlet.

To measure the above parameters, specialized instruments and equipment were used. The processing of experimental data obtained in the course of research was carried out by the well-known methods of mathematical statistics using information technologies.

\section{Results}

Theoretical and experimental studies on the use of a tractor with a hydraulically controlled towing device, carried out on the basis of the institution of higher education, the Far Eastern State Agrarian University, Amur Region, the city of Blagoveshchensk, the Russian Federation and the peasant farms of the region, have shown the validity and correctness of the chosen method of increasing the traction and coupling properties of a wheeled power plant.

It was found that the movement of the coupling point of the tractor and the trailer made it possible to reload the tractor wheels in a turn, which were in conditions of low adhesion qualities.

In general, the width of the transport corridor formed by the tractor and the trailer will be (Figure 3)

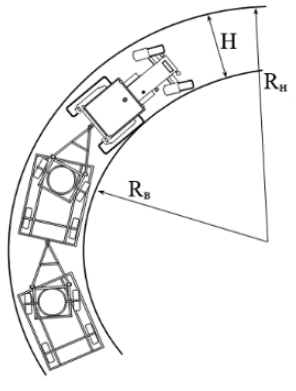

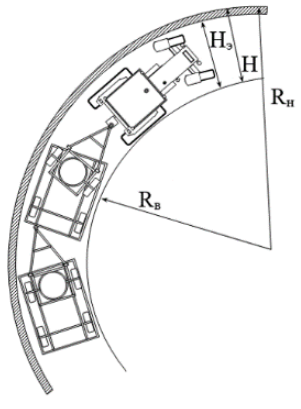

2)

Fig. 3. Tractor train turning scheme: 1) - serial the main works related to the production and transportation of crop production take place in the amur region in conditions when the surface of the 
MTU, 2) - experimental the main works related to the production and transportation of crop production take place in the amur region in conditions when the surface of the MTU

Where $R_{H}$ - outer turning radius of TTU, m; $R_{B}$ - inner turning radius of MTU, m; Hwidth of the transport corridor of serial the main works related to the production and transportation of crop production take place in the amur region in conditions when the surface of the MTU, m; $\mathrm{H}_{3}$ - the width of the transport corridor of the experimental the main works related to the production and transportation of crop production take place in the Amur region in conditions when the surface of the MTU, m.

A formula for forming the width of the transport corridor is proposed:

$$
\mathrm{H}=\mathrm{R}_{\mathrm{H}}-\mathrm{R}_{\mathrm{B}} \text {, }
$$

As can be seen from formula (1), the inner turning radius of the trailer has a great influence on the width of the transport corridor.

When the hydraulically adjustable towing device is operating, the attachment point of the trailer to the power unit moves in the longitudinal plane along a circle, the length of the arc of which is determined by the formula:

$$
l=\int_{\varphi_{1}}^{\varphi_{2}} 2 R d \varphi=\left.2 R \varphi\right|_{\varphi_{1}} ^{\varphi_{2}}=2 R\left(\varphi_{2}-\varphi_{1}\right)
$$

where $\mathrm{R}$ - the turning radius of the hydraulically adjustable towing device relative to the point relative to the attachment point to the tractor, $\mathrm{M} ; \varphi_{2}$ and $\varphi_{1}$ - angles of rotation of the hydraulically adjustable towing device.

During the operation of the hydraulically adjustable towing device, the attachment point of the trailer to the tractor in the horizontal-transverse direction is displaced by the following value $\mathrm{B}$ :

$$
\mathrm{B}=\int_{\varphi_{1}}^{\varphi_{2}} 2 R d \varphi=\left.2 R \varphi\right|_{\varphi_{1}} ^{\varphi_{2}}=2 R\left(\varphi_{2}-\varphi_{1}\right) \cos \alpha
$$

As a result of displacement of the attachment point of the trailer to the tractor, the inner turning radius of the trailer increases by the amount:

$$
\mathrm{R}_{\mathrm{H} \ni}=\mathrm{R}_{\mathrm{B} \ni}+\mathrm{B}
$$

In this case, the transport width of the corridor for the experimental the main works related to the production and transportation of crop production take place in the Amur region in conditions when the surface of the MTU with the installed device will be equal to:

$$
\mathrm{H}_{3}=\mathrm{R}_{\mathrm{H}}-\mathrm{R}_{\mathrm{H}}=\mathrm{R}_{\mathrm{H}}-\left(\mathrm{R}_{\mathrm{B} \vartheta}+\mathrm{B}\right)
$$

The analysis of formula (5) showed that when using the proposed device, the width of the transport corridor decreases in comparison with the serial the main works related to the production and transportation of crop production take place in the amur region in conditions when the surface of the MTU.

To confirm the obtained theoretical studies, experimental studies were carried out in real operating conditions.

The experiments were carried out on a dirt road used for transport goods from the fields in the location of the farm. The results of the studies carried out in the form of $3 \mathrm{D}$-models and response surfaces were built using the specialized program SigmaPlot v.11.0, while two factors were varied - the length of the hydraulic cylinder rod outlet $h_{\text {пр }}$ and the angle of deflection of the device $\mathrm{a}_{\mathrm{m}}$,

Figure 4. 

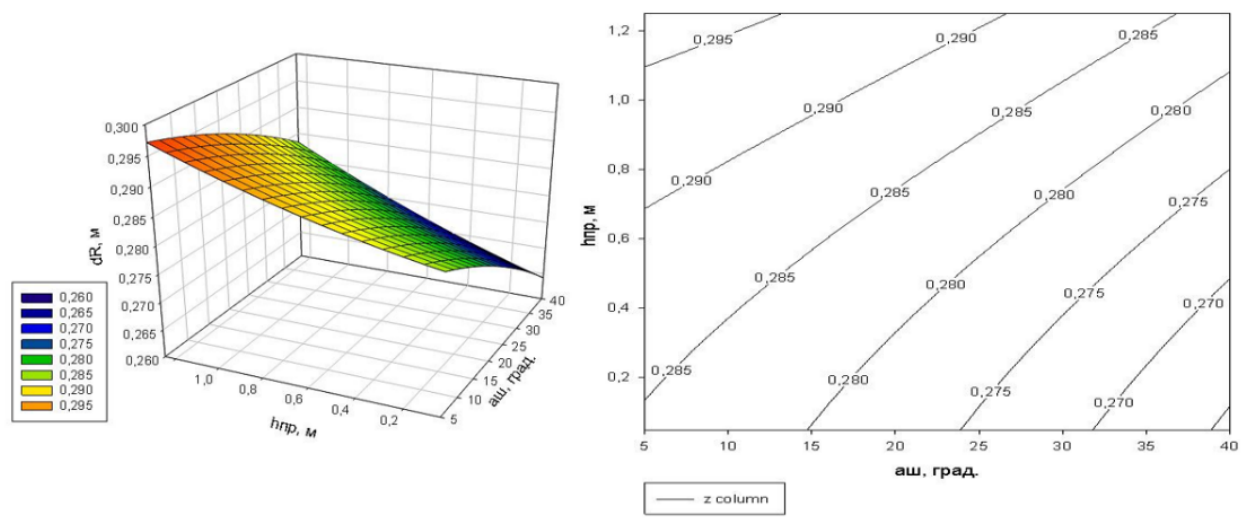

Fig. 4. The surface and cross-section of the response surface dR depending on changes in the parameters of the hydraulically controlled towing device

As a result of the analysis of variance (Figure 4), it was found that the use of the proposed device allows you to adjust the turning radius of the tractor transport train due to:

- ensuring the angle of rotation of the plan-washer installed between the tractor and the first trailer, within up to 40 degrees;

-correction of the angle of rotation of the drawbar of the trailer within the range of up to 30 degrees with the length of the output of the hydraulic cylinder rod up to $0.25 \mathrm{~m}$.

The data obtained allow us to conclude that the proposed device allows you to optimize the width of the transport corridor.

\section{Discussion}

Conducted theoretical and experimental studies carried out with a class 1.4 wheeled tractor and a 2PTS-4 trailer showed that the use of the proposed device allows to reduce the width of the the main works related to the production and transportation of crop production take place in the amur region in conditions when the surface of the MTU transport corridor in a turn by $7-12 \%$ compared to the serial the main works related to the production and transportation of crop production take place in the amur region in conditions when the surface of the MTU.

The introduction of the obtained results of research and development work into the technology of transport and technological support used in "Soyuz" in the Oktyabrsky District of the Amur Region made it possible to save energy costs up to $10 \mathrm{MJ} / \mathrm{tkm}$, which in total amounted to more than 4 million rubles when processing and harvesting crops from a sown area of 400 hectares.

The data obtained as a result of the carried out theoretical and experimental studies

The conducted theoretical, experimental studies and the obtained experimental data are within the confidence interval, which indicates their reliability, and their analysis in terms of comparing the related indicators in the previously conducted works of the authors $[9,10,11,12]$ on this issue allow to conclude that in the modern period of development of agricultural science, the presented solution is the most rational, which undoubtedly highlights the proposed methodological and technical solutions, forming a new conceptual line in the environment of applied science, in particular devoted to the study of interaction in the field of knowledge "man-machine-nature" when carrying out transport operations in agricultural production. 


\section{Conclusion}

Based on the foregoing, it can be concluded that the proposed tug-loading device is a highly efficient design that implements original ideas and has a design novelty, designed to maintain the optimal width of the transport corridor of a transport train. The research materials are widely used in the transport and technological support of the crop production technology used by "Soyuz" in the Oktyabrsky District and a number of other peasant farms in the Amur Region.

The implementation of the results obtained in production has made it possible to increase the efficiency when using class 1.4 wheeled tractors in transport operations and to obtain significant economic benefits.

Based on the results of the work, the team of authors responsibly declares that there is no conflict of interest, information data and results were obtained as a result of the activities of the entire research group. At the same time, the spent material resources are not attracted funds and belong personally to the co-authors.

\section{References}

1. N.V. Aldoshin, A.S. Pehutov, Mechanization and electrification of agriculture, 2, 26 (2012)

2. S.V. Shchitov, P.V. Tikhonchuk, I.V. Bumbar, Z.F. Krivuca, SamuiloVv, A.V. Yakimenko, O.P. Mitrokhina, Journal of Mechanical Engineering, 41(2), 31 (2018)

3. E.E. Kuznetsov, S.V. Shchitov, Increasing the efficiency of the use of mobile energy resources in the technology of cultivation of agricultural crops, 272 (2017)

4. J. Bulinski, H. Niemczyk, Ann.Warsaw Agr. Univ. Agr, 50, 3 (2007)

5. M.D. Gholkar, V.M. Salokhe, A. Keen, The Effect of axle load and tyre inflation pressure on the tractive performance of a two wheel drive tractor on soft clay paddy field, 1 (2009)

6. A.N. Kushnarev, E.E. Kuznetsov, S.V. Shchitov, Technics and equipment for the village, 6(276), 14 (2020)

7. S.V. Shchitov, E.E. Kuznetsov, Pat. for invention No. 2728162 Rus. Federation applicant and patent holder Far East state. agr. University, Application No. 2018114603, app. 13.07.2018, registered 13.07.2018, publ. 07/28/2020 Bul. No. 22.10

8. G.G. Maslov, O.N. Didmanidze, V.V. Tsibulevsky, Optimization of parameters and operating modes of machines by methods of experiment planning, 292 (2007)

9. Armando Mendes, L. D. G. Soares da Silva, Azevedo Santos Emiliana, M Jorge, Efficiency Measures in the Agricultural Sector: With Applications, 197 (2013)

10. Eric Lichtfouse, Sustainable Agriculture Reviews, Series: Sustainable Agriculture Reviews, 15, 407 (2015)

11. J. Bulinski, H. Niemczyk, Ann.Warsaw Agr. Univ. Agr., 50, 3 (2007)

12. N.F. Skuryatin, E.V. Soloviev, S.V. Soloviev, A.V. Bondarev, Methods for optimizing the design and operational parameters of tractor transport and technological units, 129 (2020) 